\title{
A luta das mulheres agricultoras: entrevista com Dona Adélia Schmitz
}

\author{
Maria Ignez Paulilo \\ Universidade Federal de Santa Catarina \\ Cristiani Bereta da Silva \\ Universidade do Estado de Santa Catarina
}

As fa las de D. Adélia Schmitz, liderança do Movimento de Mulheres Camponesas do Brasil (MMC), são recortes de entrevista ${ }^{1}$ e conversas informais mantidas desde 2000, quando ela era ainda militante e liderança do Movimento de Mulheres Agricultoras de Santa Catarina (MMA/SC). A última conversa foi bem recente e também a que inspirou a realização deste trabalho. Resultou de uma palestra seguida de debate sobre o MMC, promovida pelo Instituto de Estudos de Gênero (IEG), no dia 5 de março de 2007, e realiza da no Centro de Filosofia e Ciências Humanas da Universidade Federal de Santa Catarina (CFH/UFSC), em comemoração do Dia Internacional da Mulher.

A história de Adélia Maria Schmitz confunde-se com a história do MMA/SC. Esse movimento iniciou suas atividades ainda no início da década de 1980, no interior de Chapecó, na época na comunidade de Nova Itaberaba. ${ }^{2}$ O Movimento marcou o início de debates sobre questões específicas que envolviam as mulheres agricultoras e não apenas aquelas concementes à terra e à a gricultura. A partir de 2004 o MMA/ SC, assim como outros movimentos a utônomos de mulheres (a g ric ulto ras/tra ba lha do ra s rura is, extra tivistas, queb ra deira s de coco, pesca doras a rtesa na is, meeiras, dia ristas, a rrenda tá rias, posseiras) de outros estados, encontram-se unifica dos como um só movimento nacional: MMC.

Copyright ã 2007 by Revista Estudos Feministas

${ }^{1}$ Todas as entrevistas foram rea liza das por Maria Ignez Paulilo. Pa ra efeito deste trabalho, utiliza ram-se as entrevistase ta mbém o deba te que se seguiu à palestra de D. Adélia Schmitz na UFSC em 5 de março de 2007. As transcrições foram feitas por Iraldo Matias, Lara Bauemann, Michele Bete Petry e Valdete Bonin.

${ }^{2}$ Em 26 de setembro de 1996, Nova Itaberaba passou a ser município. 
As entre vista s rea liza da sc om D. Adélia Sc hmitz sã o muito importantes no sentido de ava lia rmosa a dequa ção das teorias de gênero disponíveis para explicar esse tipo de movimento surgido no Brasil, há mais de vinte anos, que é o MMC.

Uma das perguntas ma is rec orrentes feitas sobre o MMC é: porque, em 2004, as militantes, depois de terem se reunido várias vezes, decidiram trocaro antigo nome de Movimento de Mulheres Trabalhadoras Rurais, pelo qual era conhecido nacionalmente (embora em Santa Catarina permanecesse a sigla MMA - Movimento de Mulheres Agric ultoras), pelo atual? Duas explic ações nos foram dadas. D. Adélia nos diz que, durante um seminário, um especialista explicou-lhes que, na origem, "camponês" seria aquele que produz sua própria alimentação e essa é uma das bandeiras de luta do Movimento, traduzida pelo tema "Gênero, a groecologia e soberania e segurança a limentar", difundido no Dia Internacional da Mulher neste ano de 2007. D. Beatriz, agricultora orgânica de São J oa quim, SC, em conversa oc orrida em 2005, a firma que a mudança de nome foi uma decisão a ma durecida em diversos encontros, e que a palavra "camponês" se refere a todos que estão no campo: produtores rurais, meeiros, a gregados, quebradeiras de coco, cortadores de cana, etc.

Essas duas explicações não se excluem, complementam-se e alargam a abrangência do conceito. Para D. Bea triz, tra ba lha dores rura is sã o ta mbém c a mponeses, mesmo que traba lhem em empresa s a grícolas basta nte ca pita liza das, desde que sua atividade esteja ligada à terra. D. Adélia, em uma de nossas conversas, diz que, mesmo que a família desenvolva a produção de forma integrada à agroindústria, não significa que ela perdeu as raízes camponesas. Definir-se como camponês exige dasfamílias a produção de sua própria a limentação de forma saudável. Para D. Adélia e D. Beatriz, a concepção mais comum de camponês é a de um produtor rural de auto-sustento e renda a partir dos princípios da agroecologia.

O que a ressignificação do "ser camponês" nos diz é que a prática dessas mulheres está levando à construção de uma nova identidade. O fa to atra i logo muitas críticas. A principal delas é que o termo "camponês" não é uma categoria nativa de muitos grupos considerados como parte do campesinato nacional. Em que pese a veracidade da contesta ção, deve-se recordarque o termo a pareceu sempre em situações de luta, como foi o caso das Ligas Camponesas nos a nos a nteriores a o Golpe de 1964. J oan Sc ott, em seu belíssimo a rtigo "Experiência", nos diz que "não sã o os indivíduos que têm experiência, mas os sujeitos é que são constituídos atra vés da experiência". ${ }^{3}$ Afirma ta mbém que "a identidade é um terreno de contestação, o local de exigências múltiplas e conflitantes", e que, se não a historicizarmos, perdemos seu sentido. Portanto, tentar buscar uma 'essência' do que seria o camponês, procurando algo em comum entre aquele que

${ }^{3}$ SC OTt, 1999, p. 27 e 37. 
era assim chamado na Europa feudal e os que assim se consideram na atualidade, é um esforço vão. 0 ponto mais comum que encontramosnão está relacionado com qualquer essência, mas com a forma de relação que a sociedade inclusiva mantém com esse grupo a o longo da história, qual seja, o preconceito, como bem mostra Ciro F. Cardoso. ${ }^{4}$

Há, a inda, uma crític a ma is a ntiga, dirigida à smulheres do MMC por outros movimentos de mulheres rurais, como as milita ntes do Movimento dos Trabalhadores Rura is Sem Terra (MST) e dos Sindic a tos de Traba lha dores Rura is, rela tiva a o fa to de se reunirem entre si, com participação masculina quase nula, o que é considera do um comportamento ra dic al dema is, na medida em que 'divide a luta', ou seja, existe uma luta mais importante que todas, que é aquela baseada funda menta Imente em questões de c lasse, sendo as de gênero complementares (são 'lutinhas'). O MMC discorda; considera que as mulheres precisam de um espaço só delas. 0 homem, que é seu companheiro no dia-a-dia, também é uma fonte de repressão através do poder desigual que a sociedade lhe atribui. A desigualdade atra vessa múltiplas esferas e, talvez por isso, Céli Pinto tenha identificado nos movimentos a utônomos de mulheresuma "ra dic a lida de própria" que "corta radicalmente todas as práticas e constitui o sujeito a partir do reconhecimento e presença do corpo da mulher, a marca irredutível de sua cond içã o". ${ }^{5}$

A estratégia de se reunirem apenasentre mulheres, para poderem transformar suas insatisfações pessoa is em concepções de mundo e de justiça coletivas, encontra paralelo no comportamento que James Scott encontrou ao estudar grupos subordinados na Ásia. ${ }^{6}$ Pa ra ele, há entre seus membros dois tipos de discursos: as "transcrições públicas" e as "tra nscrições ocultas". Enquanto as primeiras estã o abertamente declaradas, as segundas são pronunciadas offstage, longe da presença inibidora dos dominadores. É nos espa ços compartilhados só por seus paresque uma explica ção coletiva, alternativa e crítica do discurso dominante pode ser elaborada. É nos encontros do MMC que as mulheres buscam uma explicação do funcionamento da sociedade a partir de suas dificuldades cotidianas, sem ter de primeiro se submeterem a uma 'politização' baseada no conceito de "classes sociais" que não encontra caminho fácil no seu diaa-dia, principalmente na relação com pais, maridos e filhos.

Teorizando sobre uma prática nascida do cotidiano, principalmente no que se refere à saúde, a limentação e meio a mbiente, va mos enc ontrar Bina Arga wal. ${ }^{7}$ Pa ra ela, c omo sã o as mulheres que cuidam da alimentação e da saúde da família, além da busca de água, lenha e outros materia is combustíveis em rema nesc entes das matas, elas se encontram em uma posição privilegiada para perceberem e tentarem

\footnotetext{
${ }^{4}$ CARDOSO, 2002.

${ }^{5}$ PINTO, 1992, p. 132.

${ }^{6}$ SCOTT, 1990.

${ }^{7}$ ARGAWAL, 1994.
} 
mudar o que lhes exige demasiado esforço e causa danos à saúde humana e ao meio a mbiente.

Bina Argawal se contrapõe à visão essencialista de Vandana Shiva e Maria Mies, ${ }^{8}$ que afirmam que a mulher está mais próxima da natureza que os homens. Entre as mulheres do MMC encontramos com freqüência visão semelhante que associa o fato de, por serem elas a darem a vida aos filhos, são elas que também têm uma grande contrib uição e podem preservar e recuperar a vida do planeta. Assim como a semente de um novo filho é plantada em seu ventre, elas cuidam para que a grande variedade de sementes crioulas não desapa reça da terra, o que lhe roubaria grande parte de sua fertilidade. Do mesmo modo, elas se preocupam com a água que faz com que tudo germine e que está sendo 'roubada' por grandes extensões de reflorestamento com eucaliptos que vêm secando rios onde se instalam.

O que percebemos, então, é que grande parte das correntes feministas temem qualquer essencialismo que aproxime a mulher da natureza, pois foi essa aproximação que levou a sociedade a - ao procurar submetera natureza a suas necessidades - subordinar ta mbém a mulher. Para as militantes do MMC, acreditarna relação entre mulhere vida é a lgo que lhes dá motivação e legitimidade para luta rem por melhores condições de alimentação e saúde, tanto da humanidade quanto da terra.

O risco que há na diferença entre as duas visões é que elas sejam retiradas do contexto da prática e levadas demasiadamente a sério por uma tendência 'missionária' de 'colonizar' o entendimento do mundo dos grupos oprimidos. O que está claro nas formas de luta do MMC é que, independentemente dos valores últimos que lhe dão suporte, é o cotidia no que lhe serve de base e estímulo. É por isso que D. Adélia diz: "as coisas ma is fá ceis de articular são a s coisas ma is práticas, [...] as mulheres querem ver os resulta dos". Elas começam no cotidia no, mas, para veros resulta dos, vão muito longe desse cotidia no como quando, em 8 de março de 2006, 2 mil mulheres da Via Campesina destruíram um laboratório de plantas da Aracruz Celulose, uma grande empresa de refloresta mento.

Adélia Schmitz nasceu no Rio Grande do Sul e vive há mais de 50 anos em Itapiranga, extremo oeste de Santa Catarina. Atua, como liderança, primeiro no MMA e depois no MMC desde 1991; são 16 anos, portanto, de luta. Começou como líderda comunida de e, em suas próp rias pa lavras, “com medo de tudo, que só sabia cozinhar, tirar leite, trabalhar na roça". Mas "foi indo", descobrindo e sentindo que tinha outras capacidades para além da administração da sua propriedade. Aos poucos, nesse processo de subjetivação, D. Adélia passou a integrara Coordenação Regional, depois a Coord ena ção Esta dual, e a tualmente está termina ndo o qua rto

\footnotetext{
${ }^{8}$ SHIVA e MIES, 1993.
} 
mandato (de três anoscada) na Executiva Estadual do MMC. Foi também durante muitos anos integrante da Coordenação da Articulação Sul $^{9}$ e durante cinco anos participou da Coordenação Nacional.

\footnotetext{
${ }^{9}$ A Artic ulação Sul passou a se organizar em 1984 com o a poio da Comissão da Pastoral da Terra e reunia, primeiramente, os esta dos do Rio Grande do Sul, Santa Catarina e Paraná. Ma is tarde passou a reunir ta mbém os esta dos de São Paulo e Mato Grosso do Sul.
} 
${ }^{10}$ Nas transcrições - tanto das perguntasquanto das respostas - foram retirados as repetições e os vícios de linguagem. Optou-se, ta mbém, em transcrever as falas respeitando o uso formal da língua portuguesa.
Maria Ignez Paulilo: D. Adélia, conte-nos um pouco sobre sua história no Movimento. ${ }^{10}$

D. Adélia: Eu fui me achando dentro do Movimento e, como coordenação nacional, trabalhei praticamente em quase todos os estados do Brasil e tive muita oportunidade também de ir pa ra conferências em outros países. Fui para vá rios países da América Latina, e a té a Índia, dois anos a trás, coisa que nunca me passou pela cabeça. Maso Movimento faza gente crescer. Eu não tive op ortunidade de estudar, estudei só a té a segunda série do ginásio, isso nos anos 60. Aí eu comecei a trabalhar no comércio, porque eu sou camponesa, morava perto da cidade e tive que ajudar os meus pa is porque o meu pai era muito doente. Então eu comecei a trabalhar no comércio para ajudara sustentar a casa. Sou a segunda de 11 filhos, eu queria estudar meio dia e trabalhar meio dia, porque o estudo era só durante o dia na época, não tinha aula à noite, e daí ou eu trabalhava o dia inteiro ou não tra ba lha va, e assim eu la rguei os estudos e só tra balhei. Depois na morei um a gric ultor, casei com um a gric ultore voltei para a roça, sou mãe de cinco filhas e um filho. A gente está dando oportunida de para eles estudarem; os que não estão formados estão cursando uma faculdade. E eu me sinto uma pessoa, assim, de muitas maneiras, privilegiada. Nunca estive doente na minha vida, estou com quase 60 anos.

Maria Ignez: Quando é que a senhora começou a participar do Movimento de Mulheres Agric ultoras?

D. Adélia: Desde 1991. De 1990 em diante já, mas eu entrei como liderança a partir de 1991. Eu comecei como líder na minha comunidade. Ea líderda comunida de ia para a reunião do município, da coordenação municipal, e tinha como ta refa repassar o que foi discutido na comunidade, para que todas as mulheres fic assem sabendo do trabalho de movimento de mulheres. Edepois eu já passei, porque o trabalho me interessou, eu gostei, [...] para a coordenação do município, e da coordenação do município passei para a coordenação regional, que são os municípios orga niza d os por proximidade, e daí fui indo para a direção no Estado, e depois já para a direção da Articulação Sul. Tudo evoluindo, não a ssim de uma hora para outra.

Maria Ignez: E o que deu na sua cabeça quando a senhora resolveu entrar para o Movimento?

D. Adélia:Eu vinha sendo convidada há muito tempo, porque eu quando jovem sempre fui uma liderança. Eu sempre tive facilidade de captar as coisas. Mas como eu morei com a 
sogra, ela era muito doente, eu não podia assumir nada. Ta mbém criei os meus seis filhos morando 20 anos com a sogra... Ela morreu com 80 anos, só depois eu comecei a militar. Então a mulherada me convidava para o Movimento, para eu dirigir. A minha sogra morreu em fevereiro, em ma rço, a bril eu já fiquei líder da comunidade. A p rimeira reunião que fui na sede do município eu acordei de coisas que eu estava fazendo errado na minha família. Porque eu era aquela mulher que queria atender a todos da melhor maneira possível. Eu trabalhava de noite, eu fazia tudo. O meu marido vinha em casa da roça, eu pegava a toalha, a roupa tudo passadinha, empilhadinha e oh! Para o banheiro. Tudo assim. Eu achava que isso era tarefa minha. Hoje eu não faço mais. "Olha, a roupa está na gaveta." Cada um sabe onde é. Cada um pega a sua. Eles ta mbém têm que fazer alguma coisa. Eu fazia tudo, tudo, tudo, ninguém limpava o seu sapato. Eu limpava todos, lustrava todos, se não tinha outra hora eu fazia de noite. Hoje não, cada um limpa o seu sapato, lustra o seu sapato. Vamos dividir tarefas, não é? E eu sempre estava em casa com a sogra. Domingo, porque quando a sogra não saía, quem estava em casa com a sogra era eu. Os outros iam para o jogo, e daí eu tirava leite de noite cedo. Tratava todos os porcos. Quando eles vinham, domingo de noite em casa, estava tudo prontinho, tudo prontinho. E o Movimento me ensinou isso. Eu acordei. Pensei: "Ah, bom!". Aí eu comecei, sem briga, eu consegui mudar. Não tra tei ma is porco, só tirei o leite das vacas. "Deixa eles fazerem depois." Eu aprendi no Movimento que tem que repartir as tarefas.

Maria Ignez: É esse o problema de a mulherficar muito presa. Dá isso que chamam o "famoso problema dosnervos", que a gente vê muito no meio rural. A senhora acha que isso afeta a mulher?

D. Adélia: Ela não vê outra coisa, não é? Eu não ligava para nada. Questões socia is? Não enxergava. Questões políticas? Não enxergava. Era aquele mundinho ali. Hoje não, muitas coisas me interessam a redor.

Maria Ignez: Mas a senhora sentia que alguma coisa não estava boa?

D. Adélia: Não, não. Eu a chava que estava fazendo o certo. As primeiras reuniões é que já me fizeram a cordar, fizeram eu sentir o gosto. Pensei: "Mas sabe que é isso mesmo!". E numa reunião, uma das primeiras também sobre a questão de gênero, ela [a coordenadora] disse: "Olha como é com facilidade que quando alguém pergunta, é com facilidade que respondemos: nós somos esposa de fulano de tal". Quan- 
do nós vamos comprar uma coisa a nota sai com o nome do seu marido. Nós ta mbém temosnome, ta mbém somosa lguém, também temos identidade. Nós não somos só a esposa de fulano de tal. Eu disse: "Mas sabe que a senhora está certa! Nós estamos fazendo tudo errado". Saí da reunião, fui no mercado, me caiu os óculos, quebrou. Fui no oculista, porque sem óculos não leio. Fui no oculista para a rrumar meus óculos. Ele disse: "Vou ter que deixar seus óculos aqui, não vou poder fazer agora. A senhora pode deixara té amanhã?". " - Posso." Daí ele pegou um bilhete: "Como é o nome do seu marido?" Bum! Me lembrei da reunião. Daí disse: "Meu nome é Adélia Schmitz". " - E o nome do seu marido?" Eu disse: "Ponha lá: Adélia Schmitz, sou eu quem está mandando a mumaros meus óculos, não meu marido". Pus logo em prática, porque logo me lembrei. Assim eu fui indo. Eu via assim com gosto. Eu a chei que estava correta aquela informação e daí fui indo. Deslanchei.

Maria Ignez: Qual é a missão do MMC?

D. Adélia: Qual é a nossa missã o? Nossa missão é a liberta çã o das mulheres trabalhadoras de qualquer tipo de opressão e discriminação. Isso se ca racteriza na organização, na forma ção e na implementa ção de experiências de resistência popular onde a s mulheres seja m protagonistas de sua história, porque não adianta eu querer libertar uma mulher se ela é oprimida. Se ela sofre violência na sua propriedade, não adianta eu querer libertá-la, ela tem que fazer a sua parte ta mbém, não é? Então ela tem que ser sujeita da sua própria história. Nossa luta é pela construção de uma sociedade baseada em novas relações socia is entre os seres humanos e desses com a natureza. Então nós queremos que também se cuide da natureza.

O MMC se caracteriza por ser autônomo: quem decide os rumos são as mulheres organizadas no $M M C$, nós não somos mandadas por sindicatos, por igrejas, nós mesmas definimos o que nós queremos. As decisões, somos nós que tomamos; somos um movimento democrátic o e popular, as mulheres têm voz e voto. O MMC busca organizar todas as mulheres tra balhadoras do campo. Somos um movimento cla ssista, das mulheres trabalhadoras do campo que compõem a classe trabalhadora. Então é um movimento de mulheres que trabalham no campo. Somos construtoras de novas relações de igualdade com as pessoas, com a terra, com a água, com a natureza e a vida como um todo. Um movimento de luta para transformar a sociedade e as relações, por isso nós já participamos de muito enfrentamento.

O MMC do Brasil se pauta em sua práxis. Em sua ação camponesa popular feminista tem os seguintes valores: a 
responsabilidade individual e coletiva de continuar na luta; respeitar as diferenças; ética; disciplina. Então essa s coisas são muito fortes: construir nova s relações; assumir a s decisões coletivas; solidariedade; a mor à luta; companheirismo; valorização da mulher. Porque nós decidimos tudo na coletividade, não existe presidente que tem a última palavra. Nós decidimos tudo no coletivo e, se antes o que eu pensei não foi vitorioso, a gente sempre se afina; o que o coletivo decidiu a gente faz: capacidade de indignar-se diante das injustiças, tra nsforma ndo nossa ind igna ção em a ção concreta de superação de novos limites; espírito de sacrifício; mística revolucionária e feminista. Isto sempre se diz, quem diz "luta" ta mb ém diz "sa crifíc io". Porque se esta mos numa mobiliza ção a s coisas, às vezes, são bem cansativas para a gente. Ma so nosso objetivo é muito mais forte do que o cansaço físico e assim por diante.

Nossa causa é a transformação da sociedade. Por isso nós lutamos: por direitos sociais, garantia de uma Previdência pública universal e solidária, salário-matemidade. Foi uma conquista nossa a aposentadoria da mulher com 55 anos e homem, 60. [Lutamos por] saúde pública integral com atendimento humanizado para todas e todos, SUS, um direito conquista do em lei; fim da violência contra as mulheres da classe trabalhadora; por uma agricultura camponesa com políticas públicas na agricultura, produção de alimentos saudáveis, soberania alimentar e reforma agrária, c rédito especial para as mulheres, que é uma luta também; defesa, preserva ção, multiplica ção e conserva ção da biodiversida de, e com monocultura a biodiversidade vai desaparecendo; acesso e garantia de documentos pessoais e profissionais, bloco de notas de produtora rural em todos os estados do Brasil, campanha nacional de nenhuma trabalha dora rural sem documentos. Nós já esta mos há muitos a nos trabalha ndo nisso e a inda há estados em que não existe o bloco de notas. Mas a grande maioria das mulheres hoje tem os seus documentos. Há uns 10, 15 anos a trás era uma minoria porque a mulheria muito na sombra do marido, se ela precisava de algum documento pegava o documento do marido, como se ela nã o prec isa sse. A partir dessa scampanha s a s mulheres começaram a se valorizar e fazer os seus documentos e o nome junto, a gente sempre trabalhou com as mulheres, o nome junto com a conta no banco com o companheiro. Tem que aprender essas coisas, e hoje tem muitas mulheres rura is com carteira de motorista e antes não existia.

As mulheres se valoriza va m tã o pouco: "Ah, se o ma rido sabe"; "Ah, se o marido tem está bom". Hoje é diferente, mas é toda uma conscientização que a gente tem que fazer em cima disso e muitas vezes a gente escutava das próprias mulheres, porque elas acham: "Ah, porque eu sou uma trabalhadora 
rural, eu posso andarde qualquerjeito". Nós temos tanto direito de se vestir bem e se a mumar como as mulheres da cidade. Nós não somos diferentes, apenas somos diferentes na profissã o, mas não em direitos. Ea gente começou a trabalha $r$ isso muito com as mulheres, e a gente escutava muito: "Ah, mas eu sou uma mulher da roça, isso são coisas para a mulher da cidade". Que nada, são coisas para nós também! Por nós sermos trabalhadoras da roça, nós não precisamos andar relaxadas. E foi justamente isso que a gente sentiu em Bra sília, nas primeiras audiências. Eu participei uma vez que nós tínhamos uma audiência marcada e nós fomos com um deputado. Chegamos à sala do dito senhor deputado, ele disse: "Não, eu agora não posso recebervocês, eu tenho uma audiência com as mulheresa gric ultoras!". E daí, sa be, eu disse: "Não, mas eu estou aqui com as mulheres". O ministro falou: "Não, não são essas mulheres, são as mulheres agricultoras que eu vou receber!". Eu disse: "Senhor, nós somos as agricultoras!". Daí eu pensei, meu Deus, como esse homem imaginou que nós vínhamos? Desleixadas, chapéu de palha na cabeça? Não sei o que ele imaginou! Porque nós também podemos nos vestir bem, a inda mais quando vamos nesses lugares, imagina! E ele saiu com essa, então não existe só a discriminação de classe. Aliás, sempre se diz que não tem disc rimina ção de classe, mas eu senti várias vezesisso na pele!

Maria Ignez: E quanto à organização do MMC?

D. Adélia: A instância máxima é a Assembléia, tanto a Assembléia Nacional como a Assembléia Estadual. Há também o Grupo de Base que é lá na comunidade onde nós moramos. As Direções Munic ipa is, as Direções Regiona is, a s Direções Estadua is, a Coordenação Nacional e a Direção Executiva. Neste ano de 2007, em Santa Catarina, é o ano das Assembléias. Depois do 8 de Março nósjá va mos começar com a disc ussão lá nas nossas comunidades, depois acontece a Assembléia Municipal, depois a gente faz a Assembléia Regional, e em outubro a grande Assembléia Estadual, isso a contece a cada 3 anos, e na Assembléia Estadual a gente tira as linhas, as priorida des que serão trabalha das nos próximos 3 a nos. Então aquela mulher lá da base, ela tem oportunidade de ajudara construir o que nós vamos fazer para a gente, como é que nós vamos trabalhar. Então isso é um pouco a orga nização do MMC.

Maria Ignez: Qua is a s coisas que são ma is fá ceis de a rtic ula r e qua is são as ma is difíc eis?

D. Adélia: As coisas ma is fá c eis de a rtic ular sã o a s coisa s ma is prátic as. Porque as mulheres querem vero resulta do das coisas. 
${ }^{11}$ A Via Campesina começou a se organizarno finaldosanos 80 , início dos anos 90 . Sua consolidação - depois de um processo marcado por diferentes reuniões, seminários e encontros, em diferentes países - deuse num Congresso, no México, em 1996, com a participação de 69 organizaçõescamponesas de quatro continentes. No presente a Via Campesina é um movimento mundial que a glutina e coordena organizações camponesas de pequenos e médios agricultores, trabalhadores agríc olas, mulheres rura is e comunidades indígenas e negras da Ásia, África, América e Europa.
Entã o foi muito ma is fácil mobilizar em prol da a posenta doria, em prol do salário-matemidade. Aí, nós mobiliza mos com facilidade. Agora, hoje, tu tens mais dific ulda de de mobilizar porque a coisa não a pa rece tão concretamente. Por exemplo, a gora tu va is mobiliza r pela luta da Previdência e a dificulda de é tu conseguires..., então a coisa se toma visível. As mulheres querem ver os resulta dos.

Maria Ignez: O movimento das mulheres camponesas tem bandeiras específic as levantadas. Gostaria de saber qual é a relação ou como é que vocês se articulam com outros movimentos?

D. Adélia: Entidades ou movimentos internacionais. Com entidades e movimentos que constituem o conjunto da Via Campesina Internacional, ${ }^{11}$ organiza ção de mulherese outras entidades, as qua is têm por orientação princípios de acordo com o MMC. Então hoje nós não estamos só a rticuladas em nível de país, porque nos outros países também existem movimentos de mulheres camponesas. Então hoje já a contecem conferências mundia is das mulheres do campo e nós participamos sempre delas. Aconteceu na Índia, no México, nem me lembro mais de todos os países, geralmente Santa Catarina tem representação nessas conferências. E a contecem também a sconferências do Cone Sul, a contecem as conferências la tino-americanas de que nós também participamos. Então a gente vê com bons olhos, e eu tenho muita esperança para frente, porque essa questão das sementes, o resgate das sementes crioulas, produzir as sementes na propriedade, os gêneros alimentícios, são milha res de grupos pelo mundo afora que trabalham. Então, quando eu fui para a Índia tivemos um dia de estudo sobre sementes, lá nós está va mos em quase 200 lideranças da Via Campesina Mundial. Fazem parte da Via Campesina os movimentos ligados ao campo em nível intemacional, existem a Via Campesina aqui no Estado, a Via Campesina Nacional, a Via Campesina Latino-Americana e a Via Campesina Mundial que se articulam. Porque achamosque um outro mundo é possível, mas ele tem que ser construído, porque nada vem de graça.

A rela ção com os outros movimentos, então, como nós fala mos antes da Via Campesina, então nós nos enquadramos nas decisões da Via Campesina Nacional. Da Via Campesina fazem parte o MST, o MAB, que são os a ting id os por ba rra gens, o MPA [Movimento de Pequenos Agricultores], a PJ R, que é a juventude rural, o MMC, a CPT [Comissão Pastoral da Terra], Feab [Federação dos Estudantes de Agronomia do Brasil], que somos nós, e tem certas [organizações] que estão junto, que são organizações do campo. Então a gente centraliza as decisões essenciais de construção do Projeto. Então a nossa 
rela ção com os outros movimentos é pacífica, e quando nós temos as lutas maiores nós nos juntamos, trabalhamos todos juntos. A gente soma, o que nos une. Equando há atividades das mulheres da Via Campesina, também como nessa a tivida de aqui [a pa lestra na UFSC, em 5 de março de 2007], nós temos a relação com mulheres do MAB, do MST, do MPA, que estão junto conosco, a qui nessa a tividade.

Maria Ignez: Como é que o Movimento se mantém?

D. Adélia: Quanto à sustentação do Movimento, muito vem das próp rias mulheres. E nós ta mbém tivemos a lgumas a judas de cooperação internaciona is. Certas coisas de formação, a té uma ou outra emenda parlamentarem nível na cional. [...] Nós tivemos uma na linha da saúde, nós fizemos 40 e poucos seminários de saúde em diferentes municípios [... ]. Então são projetos específicos para certas atividades e nisso também entra o material, elaboração de cartilhas na saúde e assim pordiante. Masmuito vem das própria smulheres, porque cada município paga um valor X porano, o município paga para 0 Movimento, a regional paga um pouco ta mbém, então é assim do jeito que está, mas falta muito dinheiro para fazermos as a tividades!!! Muita coisa com certeza podia ser muito diferente, podia ir ma is rápido se a gente tivesse a condição financeira. E muitas vezes a gente faz até onde a gente consegue caminhar, porque tu não fazes nada sem dinheiro. É como agora os ônibus que virão [do interior para Florianópolis, para as a tivida des do 8 de Março], muito vem dasprópriasmulheres, porque não se tem uma condição financeira para pagar os ônibus. A gente pede ajuda nas prefeituras, nos sindicatos, para os lugares que der. 0 que vem, vem bem, mas o que não está garantido vem das próprias companheiras.

Maria Ignez: Essas reuniões intemaciona is sobre as quais a senhora falou são aquelas reuniões da ONU de 1985, 75, ou são outras reuniões?

D. Adélia: Outras reuniões, [como o] Fórum Social Mundial. Aí a gente vai se conhecendo e vamos nos articulando com outras organizações de mulheres, ta mbém atra vés da Via Campesina com lideranças que moram no campo e atuam em organizações do campo. Também o MMC participou de reuniões sobre os impactos da Organização Mundial do Comércio sobre a agricultura camponesa.

Maria Ignez: Há muito tempo eu venho acompanhando o movimento de mulheres, e nas relações mantidas entre vocês e o sindicato e o MST percebia-se que antigamente havia a lguns pontos de conflito. Por exemp lo, qua ndo eu entrevista va 
as mulheres no sind ic a to, os/as sind ica listas a chavam que as mulheres não deveriam se reunir só entre as mulheres. Então, há alguns pontos comuns e alguns pontos de conflito. 0 que a senhora indicaria como pontos em comum e como pontos ainda de tensão?

D. Adélia: Nós fomos muitas vezes questionadas também por entidades internacionais. Quando eu era presidente em nível nacional, a gente estabelecia relações com entidades de outros países. Então nós sempre fomos questionadas: por que um movimento só de mulheres? Porque tem o MSTque orga niza ta mbém as mulheres, tem o MPA que organiza as mulheres, tem o MAB que organiza as mulheres. Então eles achavam que a gente devia se a gregara uma organização dessas, a o invés de um movimento só de mulheres. Masqualé o problema que nós sentimos? Nesses movimentos mistos, nos poderes de decisão estão geralmente os homens. São poucas mulheres que estã o nos espaços onde se decidem ascoisas. As mulheres são muito mais tarefeiras, mandadas pelos homens, do que ocupando espaços de decisão. E nós queremos um espaço onde nós decidimos, por isso nós achamos importante um movimento só de mulheres. Num movimento misto, onde está o homem e a mulher, muitas vezes a mulher se cala e não fa la o que talvez ela gosta ria de falar. E num espaço só de mulheres nós a chamos que é mais fácil as mulheres se abrirem.

Maria Ignez: Sabe que há um autorque fala isso? Ele pesquisou camponeses na Ásia e se chama James Scott. Ele fala que qua ndo as pessoas são oprimid a s elas têm ma is de um disc urso. Têm um discurso que é para o palco, que se fala para todo mundo, e têm um discurso que é aquele baixinho, que se faz a trás do palco. Então ele diz que as pessoas oprimidas têm que se reunir para criar seu próprio discurso, um discurso delas, porque senão estão sempre bloqueadas. Então J ames Scott fala sobre o discurso do palco e o discurso fora do palco, que é esse que só se pode fa zer com aspessoas iguais, senão nã o se constrói o disc urso. Va i-se fo mula ndo um contra disc urso, como ele fala. A senhora concordaria com James Scott?

D. Adélia: De certa forma eu acho que sim, porque esses bloqueios normalmente têm muita violência, discriminação, exploração, e que não é tão fácil se libertar, porque nós herdamos uma cultura de suportar, silenciar, obedecer, e enfrentar isso exige força interior.

Maria Ignez: A senhora falou que 19 estados já têm o MMC. Quais são os estados que estã o fora? 
D. Adélia: São Paulo está fora, Rio de Janeiro está fora, e, no Nordeste, Pemambuco acho que está fora. Amapá não tem.

Maria Ignez: A senhora tem a lguma explic ação por que esses estados querem fic ar fora?

D. Adélia: Lá o MSTé ma is forte e nós nã o conseguimos a inda referências. Vá ria s referênc ias nós já tínha mos, vá ria s tenta tivas nós já fizemos, mas ainda não a chamos lideranças de sustentação que de fato continuaram a articular e trabalhar, liderança que assumisse a causa da mulher camponesa. Mas são os esta d o s ond e a s outra sorg a niza ções sã o ma is fortes, O MPA, o MST, entã o a s mulheres se a rtic ula m ma is com essa s org a nizações. Não tem movimento só de mulheres, mas não quer dizer que não tenha nada de organização, são outros movimentos.

Maria Ignez: Em outras entrevistas que fiz, durante todos esses anos, vocês diziam que o MMA tinha uma vantagem: ele era mais livre que o sindicato, pois no sindicato era necessário aprovar tudo em várias instâncias e no MST era igual, e que vocês eram muito mais livres, só organizar, era rápido, enfim. Agora com essa nacionalização ficou mais rígido? Tem que passar por muitas Assemb léias antes?

D. Adélia: Não, a gente conversa entre a gente, e a disc ussão para a Assembléia vem lá da base, primeiro Assembléia Munic ipal, Assembléia Regional e depois Assembléia Esta dual. Nós temosas linhas polític as, essências, princípios, cada região precisa levar em conta sua realidade, a cultura, o modo de vida das mulheres e fazer o Movimento.

Maria Ignez: Porque me lembro também que alguns nos sind ic a tos dizia m: "Ah, nos encontros de mulheres é só a quela chora deira". Porque as mulheres se emociona va m e chora vam. Não sei se a senhora chegou a ouvir isso?

D. Adélia: Nunca escutei falar. Mas depende que choradeira que estão falando? Quando trabalhamos a questão da luta contra a violência há choro. Porque a dor, o sofrimento, as ameaças são muito grandes. A violência que permeia as famílias a gente não imagina, e muito poucas vezes vem a público. Isso fica escondido e vem da cultura patriarcal e capita lista que estabelece relação de exploração e violência. Mas já participei de várias choradeiras nos encontros. Eu já partic ipei em muitos momentos em que a gente chorava junto com as mulheres, porque para a gente foi emocionante. Porque tu conseguiste a confiança delas, para elas falarem o que em espaço nenhum elas tinham falado. Isso para a gente é uma conquista, tu conquistares um grupo, falar de coisas 
que as mulheres choravam e diziam: "Eu nunca tive coragem de dizer isso a qui em luga rnenhum". E a gente as incentivava: "Não, solta tudo, solta tudo, pode falar o que está te atrapalhando, o que está te fechando, solta tudo, porque tu tens o direito de ser uma pessoa livre. Se tu começares a falar, quem sabe as coisas fic am mais fáceis". Eu assisti em muitos momentos às mulheres chorarem. Coordenei uma vez um encontro em que a líder disse para mim..., era um curso de formação de três dias em que se entrava um pouquinho nas particularida des ta mbém, daíela me dizia: "Tem que irdevagar, a s mulheres são conserva doras, elas dific ilmente vão se abrir". E daí pensei: "Poxa, quem sabe não vou conseguir nada, mas vou tentar". Gente do céu! Mas eu chorava com as mulheres! Gente! O que eu escutava! Quanta opressão! Quanta dominação! E elas começaram a soltar. Agora, se tivesse um homem junto isso teria a contecido? Não teria a contecido, por isso é importante um espaço só para as mulheres. Uma s coisa s das mais absurdas que tu escutavas, e elas choravam e falavam, choravam e falavam. Isso para mim foi uma grande conquista, e eu dizia para as mulheres: o que cai aqui dentro dessa sala tem que ficar aqui, isso não são coisas para se comentar lá fora. Essa disciplina todas têm que ter, não é? Isso nós temos que assumir no grupo, e todas concordaram. Eu nunc a escutei mulher nenhuma fala ro que sa iu lá dentro. Então tem que ter disciplina assumida. Isso, pa ra mim, foi uma grande conquista, consegui fazer a pessoa se soltar para falar, sem ter feito um curso de psicologia. Mas a psicologia tu podes praticar ta mbém, tu a prendes ta mbém fazendo as coisas.

Maria Ignez: Uma vezuma pesquisa dora disse que as mulheres do movimento de mulheres já tinham pertencido a sindicatos, etc. e tinham decidido vir para o movimento de mulheres, e a Lucy [Choinacki] tem achado que não, que era mais fácil as mulheres do MMA, na época, irem para o sindicato...

D. Adélia: Não, nós somos parte do sindicato.

Maria Ignez: Mas, por exemplo, para ser liderança, é comum uma liderança de sindic a to de repente deixaro sindicato e ir para o MMC, ou não? Ou é ma is fácil o contrário?

D. Adélia: Acontece, qua ndo isso a contece é o contrá rio. Mas acho que é maisfácil ela ir do Movimento para o sindic a to do que do sindicato para o Movimento, porque o Movimento exige, e o retomo financeiro, às vezes, é melhor no sindicato. Porque o sind ic a to tem uma estrutura que nós não temos. Então lá o trabalho se toma ma is fá cil que o nosso. Porque a estrutura permite, e não exige, não exige tanto de luta, sacrifício, igual se exige no Movimento. 
Maria Ignez: Uma vez entrevistei uma líder sem terra, e ela falou para mim: olha, é o seguinte, o MST luta por terra; o sindic a to, agricultura familia r; e o MMA é saúde.

D. Adélia: E a Previdência?

Maria Ignez: Então, como é que a senhora veria isso?

D. Adélia: Não, tem lógica isso. O MST luta por terra... mas precisa de política para o campo, porque com terra, só com terra hoje ninguém resolve mais nada. Então eles cha mavam a luta por saúde de 'lutinha' das mulheres.

Maria Ignez: Quem que chamava?

D. Adélia: Ah, a s outra sorga nizações, 'a lutinha da s mulheres'. Então, mas quem ma is puxou a luta pela Previdência foram as mulheres. Enós não estamospensando a penasem nós, porque lutamos também pela a posentadoria dos homens, da família, do bem-estar. Mas, sabe, às vezes, existem essas coisas de 'picuinhagem', como existem em todos os espaços. Nós já esc uta mos muitas vezes: "Ah, as mulheres com a sua lutinha pela saúde". Mas, e se não tivesse saúde, o que os outros iriam fazer? Nós não lutamos só pela saúde das mulheres, nós luta mos pela saúde do povo. Estamos investindo na produção de a limentos sa udá veis a partirdosprincípios da a groecologia, na reeducação a limentar, na diversific ação da produção, na recuperação das sementes crioulas, enfim estamos dando nossa contribuição na construção do projeto popular de agricultura camponesa.

Maria Ignez: A senhora falou na palestra que vocês são segurados especiais, e fiquei curiosa: por que são especia is?

D. Adélia: Porque o segurado especial não contribui com a Previdência como o tra ba lha dor urbano; nós contribuímos pela produção que nós vendemos. De toda a produção que vendemos da roça: vendemos feijão, vendemos leite, vendemos suínos, ou soja, ou milho, o que for; sã o desc onta dos $2,5 \%$ que vai pra o Funrural e no fim cai lá na Previdência. Esses 2,5\%, quem vende muito contribui muito, mas há a queles que praticamente vendem pouquinho durante o ano e contribuem pouco, mas o benefício é igual para quem é considerado segurado especial. Somos segurados especia is porque não trabalhamos só 8 horas por dia. Não temos final de semana e feriados livres como os urbanos, não temos seguros diante dasintempéries. Se morre uma vaca, não temos indenização, e muitas vezes é nosso ganha pão. Precisamos organizar nós mesmas muitos serviços que são obrigação do 
Estado: o esgoto, a infra-estrutura da propriedade, rede de água, o cuidado dos doentes, das crianças, dos idosos. Os segurados especiais têm que ser garantidos pelos cofres públicos para receber o benefício da aposentadoria. Nós temos que comprovar a profissão de trabalhadora rural.

Maria Ignez: E existe ma is alguma categoria que é segurado especial, ou só o a gricultor?

D. Adélia: Não, é todo trabalhador rural, a gricultor, as pescadoras artesana is e outros.

Maria Ignez: E existe algum projeto para que o dinheiro não saia da Previdência, e sim saia de algum outro lugar?

D. Adélia: 0 dinheiro tem que sair dos cofres públicos. 0 governo tem que implantar medidas de enfrentamento à sonegação, impedindo que as grandes empresas fiquem ina dimplentes com a Previdência Social e seja m beneficiadas pormecanismos de renegociação de dívidas, incentivosfisca is e outros mecanismos. Também a cha mos que o govemo deve incorporar a o financiamento da seguridade social a contribuição sobre grandes fortunas, a taxação sobre transa ções financeiras internaciona is, a contribuição sobre a movimentação financeira, e que a contribuição sobre o faturamento do setor do agronegócio seja destinada ao pagamento dos benefícios dos segurados especia is. Se o dinheiro da Previdência fosse usa do só para a Previdência..., masse pega para pagara dívida externa, para fazerum monte de coisa, menos aquilo..., então...

Maria Ignez: Essa aposentadoria da dona de casa da Lucy [Choinacki], então, acho que será também aposentadoria especial, não é? Vai ser nesta linha?

D. Adélia: É, tem que cair nesta linha. Mas ela já é um pouco diferente de novo porque asdonasde casa que se enquadram na aposentadoria das donas de casa são apenas aquelas mulheres em que o marido não ga nhe ma is do que do is salários mínimos. Se o marido ga nha rma is do que dois sa lá rios mínimos, elas não se enquadram mais.

Maria Ignez: Mas há um projeto, parece de um deputado, ou de um senador, que prevê a cobrança de INSS, como se fosse o INSS dos agricultores...

D. Adélia: Sim, porque agora na reforma da Previdência existe essa disc ussão da contribuição ind ividual, que o a gricultor tem que pagar uma certa porcentagem sobre o salário mínimo 
mensa Imente para a Previdência. [...] Mas nós esta mos lutando para garantir os direitos previdenciários como está na Constituição e garantir a condição de seguradas especia is.

Maria Ignez: E vocês são favorá veis ou contrárias?

D. Adélia: Não, nóssomos contra, porque uma grande parcela da população vai cair fora porque não tem condições.

Maria Ignez: Quando as mulheres invadiram aqueles laboratórios da Aracruz Celulose e destruíram as mudas, eu escrevi um artigo mostrando as razões delas, e fui muito criticada.

D. Adélia: As mulheres também foram criticadas, mas foram muitos os escritos a favor das mulheres.

Maria Ignez: Você sabe que isso um amigo meu falou, porque falei: "Estou tão triste porque todo mundo está falando mal". Eu escrevi um artigo, saiu aqui no jomal da universidade, no Ambiente Brasil. Até mandei, não sei se chegou no MMC. Aí ele falou: "Você está enga na da, o pessoal assustou, sim, muita gente ficou pensando". Agora a senhora está me dizendo a mesma coisa. Levaram um susto, sim, estão tomando ma is cuidado. Então a senhora pensa que realmente impactou?

D. Adélia: Claro, porque a monocultura mata a biodiversidade; debaixo de um matagal de eucalipto nem asformigas se cria m, mata a terra! Mata a vida! Porque a terra possui vida. Nem uma abelha, nada vai nessas árvores, e a biodiversidade onde é que fica? A quantidade de água que esses eucaliptos absorvem da terra! As mulheres defendem a vida e querem que as futuras gerações também tenham condições dignas de viver. A função social da terra é produzir comida.

\section{Referências bibliográficas}

ARG AWAL, Bina. A Field s of One's Own: Gender and Land Rights in South Asia. Ca mbridge: C a mbridge University Press, 1994.

CARDoso, Ciro F. "Camponês, campesina to: questões aca dêmicas, questões políticas". In: CHEVITARESE, André Leona rdo (Org.). O campesinato na história. Rio de J a neiro: Relume Dumará/FAPERJ, 2002. p. 19-38.

PINTO, Céli R. "Movimento socia is: espaços privilegiados da mulher enqua nto sujeito político". In: COSTA, Albertina de Oliveira; BRUSC HINI, C ristina (O rgs.). Uma questão de gênero. Rio de J a neiro: Rosa dos Ventos; São Paulo: Fundação Carlos Chagas, 1992. p. 127-150. 
SC OTT, J a mes C. Domination and the Arts of Resistance: Hid den Transcripts. New Haven and London: Yale University Press, 1990.

SC OTT, J oa n W. "Experiência." In: SILVA, Alc ione Leite da; LAGO, Mara Coelho de Souza; RAMOS, Tânia Regina Oliveira (Orgs.). Falas de gênero. Florianópolis: Mulheres, 1999. p. 21-55.

SHIVA, Vandana; MIES, Maria. Ec ofeminism. Ha lifax, Nova Scotia: Fernwood Publications; London \& New Jersey: Zed Books, 1993. 